\title{
Therapeutic Potential of Cinnamomum Zeylanicum Extract to Mitigate Hyperglycemia
}

\author{
Muhammad Ahmar Jahangir, ${ }^{1}$ Aamir Shehzad, ${ }^{2}$ Masood Sadiq Butt, ${ }^{3}$ Muhammad Shahid ${ }^{4}$
}

\begin{abstract}
Background: Nutrition and health have become one of the most intriguing focuses in the world today. Technological advancement, nutritional imbalances and sedentary lifestyle have ascended numerous health issues worldwide. Scientific evidences have provided the chemo-preventive and chemotherapeutic role of dietary phytochemicals to cure these ailments. Cinnamon (Cinnamomumzeylanicum) has been utilized as a potential therapeutic agent in various cultures for centuries.
\end{abstract}

Objective: Trans-cinnamaldehyde (3-phenyl-2-propanal) contributes as a major constituent of cinnamon bark oil approximately about $49.9-62.8 \%$ of the total amount and has hypoglycemic, hypocholesterolemic and anticancer potential.

Methods: The ethanolic and supercritical fluid

\footnotetext{
${ }^{1}$ National Institute of Food Science and Technology

University of Agriculture, Faisalabad

${ }^{2}$ National Institute of Food Science and Technology

University of Agriculture, Faisalabad

${ }^{3}$ National Institute of Food Science and Technology

University of Agriculture, Faisalabad

${ }^{4}$ Department of Biochemistry

University of Agriculture, Faisalabad
}

Date of Submission: 15-03-2017

Date of $1^{\text {st }}$ Revision Received: 15-05-2017

Date of Acceptance for Publication: 20-06-2017

Conflict of Interest: None

Funding Source: None

\section{Contribution}

All Authors have contributed in Study Design, Data Collection, Data Analysis, Data Interpretation, Manuscript Writing and Approval. extracts of cinnamon bark were subjected to in vivo modelling to evaluate the hypoglycemic potential of cinnamaldehyde. Purposely, efficacy trial was performed on normal and hyperglycemic Sprague dawleyrats for 8 weeks. Three types of diets i.e. normal $\left(\mathrm{D}_{0}\right)$, nutraceutical containing $0.5 \%$ conventional extract $\left(\mathrm{D}_{1}\right)$ and nutraceutical containing $0.1 \%$ supercritical fluid extract $\left(D_{2}\right)$ were used throughout the study.

Results: Feed \& drink intake and body weight were increased during the trial. Serum analyses exhibited the maximum reduction $11.65 \%$ in glucose level in hyperglycemic rats as an effect of diet $\mathrm{D}_{2}$ followed by $\mathrm{D}_{1}$ which depicts $9.94 \%$ reduction. Nutraceutical diet $\mathrm{D}_{2}$ also increased the insulin level up to $7.23 \%$ in hyperglycemic rats whereas this increment was $2.37 \%$ in normal rats.

Conclusion: The current research helps us to conclude that cinnamon extract is effective against hyperglycemia.

Keywords: Cinnamaldehyde, Hyperglycemia, Nutraceutical, Antioxidant.

\section{Introduction}

Across the globe, nutritional imbalances in the diet are causing a number of physiological dysfunctions which engrossed the adoption of diet based therapies as an intervention against various infirmities. Amongst principal therapeutic tool of apposite dietary guidelines, the use of functional and nutraceutical food provides an opportunity to alleviate these health problems within the population. ${ }^{1}$ Overwhelming evidences from epidemiological and biological studies have illuminated the extensive use of plant based products owing to their rich phytochemistry against numerous ailments. Hence, dietary approbations for the prevention and cure of chronic diseases have emphasized the con- 
sumption of variety of plant foods. ${ }^{2}$ Spices having a virtuous recognition in cultural heritage and food appreciation possess pivotal health linkages and have also been used effectually in ethnic system of medicine. Being common dietary adjunct, spices contribute as a source of numerous bioactive compounds which influence various digestion and metabolic processes. Spices rich in polyphenols, inhibit oxidation processes in food products and exhibit health promoting effects by increasing antioxidative potential of the body on consumption. ${ }^{3}$ Amongst spices, cinnamon (Cinnamomumzeylanicum) belonging to family Lauraceae has been utilized as a potential therapeutic agent in various cultures for centuries. Cinnamon bark is one of the oldest known spices used against gastrointestinal complaints, chronic bronchitis and inflammation of eyes in ayurvedic medicine for over 6000 years. ${ }^{4}$ The major constituents of cinnamon bark oil includes $75 \%$ cinnamaldehyde, 5\% cinnamyl acetate, $3.3 \%$ caryophyllene, $2.4 \%$ linalool and $2.2 \%$ eugenol. ${ }^{5}$

Diabetes mellitus is a chronic metabolic disorder that affects about $4 \%$ of the world's population and is expected to upsurge by $5.4 \%$ in $2025 .^{6}$ According to W.H.O. prediction, diabetes will become the $7^{\text {th }}$ leading cause of mortality worldwide by the end of 2030 . $^{7}$ They projected the diabetes prevalence with total number of people affected will increase from 171 to 366 million between 2000 and $2030 .^{8}$ It is also associated with abnormalities in body's metabolism which ultimately leads to numerous other complications like an increased risk of cardiovascular disease, neuropathy, retinopathy and nephropathy in addition to damaging liver, kidney and beta-cells of pancreas. Improvements in glycemic control have proved to be beneficial in reducing the risk of these complications. Consumption of cinnamon has been found effective in improving the glycaemic control and also reduces the onset and progression of diabetes. ${ }^{9}$

Cinnamaldehyde (3-phenyl-2-propanal) represents the main constituent of the cinnamon bark oil contributing about 49.9 to $62.8 \%$ of the total amount. ${ }^{10} \mathrm{It}$ provides protection against metabolic syndromes, cardiovascular complications and diabetes. Functionality of insulin receptors is improved by virtue of enzyme activation (insulin receptor kinase) which is responsible for insulin binding to the cells. Likewise, it is also responsible for hindrance in the enzyme (insulin receptor phosphatase) activity that impede this process, ultimately leading to the maximum phosphorylation of insulin receptor, which is associated with improved insulin sensitivity. Additionally, glucose tolerance is also increased by reducing effect of cinnamaldehyde on activity of hexokinase and glycogen content in the liver and skeletal muscles. Cinnamon polyphenols contribute to the regulation of various proteins like glucose transporter 4 (GLUT4), insulin receptor $\beta$ and tristetraprolin involved in insulin signal transduction pathway. ${ }^{11}$ Recent research illustrates that cinnamaldehyde contributes positively towards consumers health by reducing glucose, cholesterol and LDL levels.

\section{Materials and Methods}

The dried cinnamon (Cinnamomumzeylanicum) bark was procured from local market and ground to obtain particle sizes in the range of $300-500 \mu \mathrm{m}$ for further analyses. The reagents (analytical and HPLC grade) and standards were purchased from Merck (Merck KGaA, Darmstadt, Germany) and Sigma-Aldrich (Sigma-Aldrich Tokyo, Japan). For efficacy trial, male Sprague Dawley rats were acquired from National Institute of Health (NIH) Islamabad. housed in the Animal Room of NIFSAT. For biological assay, diagnostic kits were purchased from Sigma-Aldrich, Bioassay (Bioassays Chemical Co. Germany) and Cayman Chemicals (Cayman Europe, Estonia).

The cinnamon extracts were prepared using ethanol and water $(50 \% \mathrm{v} / \mathrm{v})$ for a period of $60 \mathrm{~min}$ with constant temperature of $50^{\circ} \mathrm{C}$ following the outlines of Mariod et al. ${ }^{12]}$ Resultant solvent extract was filtered and recovered through Rotary Evaporator (Eyela, Japan). Cinnamon powder was subjected to supercritical fluid extraction system (SFT-150 Supercritical Fluid Technologies, Inc.) to obtain supercritical fluid extracts using $99.8 \%$ pure $\mathrm{CO}_{2}$. Accordingly, sample was placed in $100 \mathrm{~mL}$ extraction vessel followed by Optimization of $\mathrm{CO}_{2}$ at 5000 psi while maintaining time and temperature conditions constant. ${ }^{13}$

The bio evaluation trial was conducted to investigate the therapeutic potential of cinnamaldehyde against hyperglycemia. Purposely, seventymale Sprague Dawley rats were procured from National Institute of Health (NIH) Islamabad and housed in the Animal Room of National Institute of Food Science and Technology, University of Agriculture Faisalabad. Intentionally, rats were acclimatized by feeding on basal diet for a period of one week under environmentally controlled conditions of temperature $\left(23 \pm 2^{\circ} \mathrm{C}\right)$ and relative humidity $(55 \pm 5 \%)$ along with $12 \mathrm{hrs}$ light-dark period. At the initiation of study, some rats were 
sacrificed to get baseline trend of selected biochemical parameters. During efficacy trial of sixty days, two

Table 1: Different Studies Conducted during Efficacy Trials.

\begin{tabular}{|l||l||}
\hline Study I & Normal rats \\
\hline \hline Study II & Hyperglycemic rats \\
\hline
\end{tabular}

types of studies were conducted separately in order to determine the therapeutic effect of conventional solvent extract (CSE) @ $\mathbf{0 . 5 \%}$ and supercritical solvent extract (SFE) @ $0.1 \%$ on selected parameters such as lipid profile, glucose and insulin level. Study I comprised of rats fed on normal diet, whereas high sucrosediet was administrated to induce hyperglycemia in study II (Table 1). The composition of diets given to rats is presented in Table 3. On the basis of administrated diet, each study was further subdivided into three groups containing 10 rats in every group. During 60 days trials, simultaneous provision of nutraceutical $\mathrm{CSE}_{\mathrm{CS}}$ $\left(\mathrm{D}_{1}\right)$, nutraceutical $\mathrm{SFE}_{\mathrm{SE}}\left(\mathrm{D}_{2}\right)$ diets along with control $\left(\mathrm{D}_{0}\right)$ were given to respective groups (Table 2).

Table 2: Efficacy Study Plan.

\begin{tabular}{|c|c|c|c|c|c|c|}
\hline \multirow{2}{*}{$\begin{array}{c}\text { Studies } \\
\text { Groups }\end{array}$} & \multicolumn{3}{|c|}{ Normal rats } & \multicolumn{3}{|c|}{ Hyperglycemic rats } \\
\hline & 1 & 2 & 3 & 1 & 2 & 3 \\
\hline Diets & $\mathrm{D}_{0}$ & $\mathrm{D}_{1}$ & $\mathrm{D}_{2}$ & $\mathrm{D}_{0}$ & $\mathrm{D}_{1}$ & $\mathrm{D}_{2}$ \\
\hline
\end{tabular}

$\mathrm{D}_{0}$ : Control diet: $\mathrm{D}_{1}$ : Diet containing nutraceutical $\mathrm{CSE}_{\mathrm{CS}}$ :

$\mathrm{D}_{2}$ : Diet containing nutraceutical $\mathrm{SFE}_{\mathrm{f}}$

It is assured that all the bioefficacy trials were performed in compliance with the institutional guidelines and relevant laws of the National Institute of Food Science and Technology, University of Agriculture Faisalabad, Pakistan. Additionally, allthe experimental modeling embraces dietary and safety plans were reviewed and approved by the institutional committee(s).

Feed intake of individual group of rats was measured daily by subtracting the remaining diet from the total diet during the whole trial. Likewise, water intake of each group was also recorded on daily basis. ${ }^{14}$ Gain in body weight of experimental rats was measured weekly throughout the study period to monitor any suppressing effect of cinnamaldehyde enriched diets.

Table 3: Composition of Experimental Diet.

\begin{tabular}{|l||c||c||}
\hline Ingredients (\%) & Normal Diet & $\begin{array}{c}\text { High Sucrose } \\
\text { Diet }\end{array}$ \\
\hline \hline Corn starch & 82 & 42 \\
\hline \hline Corn oil & 10 & 10 \\
\hline \hline Casein & 4 & 4 \\
\hline \hline Minerals & 3 & 3 \\
\hline \hline Vitamin mixture & 1 & 1 \\
\hline \hline Sucrose & - & 40 \\
\hline
\end{tabular}

In each study, the collected sera were evaluated for glucose concentration by GOD-PAP method as described by Sailesh and Padmanabha ${ }^{15}$ whereas, insulin level was assessed following the procedure descrybed byAhn et al. ${ }^{16}$ Serum lipid profile of rats including total cholesterol, low density lipoprotein (LDL), high density lipoprotein (HDL) and triglycerides were measured according to their respective protocols. Triglycerides and cholesterol level in sera samples were determined by liquid triglyceride (GPO-PAP) and CHOD-PAP method respectively, outlined by Vafa et al. ${ }^{17}$ Likewise, HDL of serum samples using cholesterol precipitant method and LDL were analyzed as per guidelines of Alshatwi et al. ${ }^{18}$

The resultant data were examined through completely randomized design (CRD) by employing Cohort version 6.1 (Costat-2003). Moreover, level of significance was measured using analysis of variance (ANOVA) following the principles outlined by Steel et al. ${ }^{19}$

\section{Results}

Efficacy studies were performed in vivoon male Sprague Dawley rats in order to determine the functional and nutraceuticalimportance of cinnamon extract against hyperglycemia. For this purpose, rodent experimental modeling was used instead of human subjects because of appropriate supervision, easy handling, feasibility ofcontrolled environmental conditions and 
safety concernsrelating to active ingredient (cinnamaldehyde) being used.

Mean values for (study I) explicated feed intake 13.92 $\pm 0.46,14.45 \pm 0.63$ and $14.87 \pm 0.52 \mathrm{~g} / \mathrm{rat} /$ day at initiation that raised to $18.65 \pm 0.71,19.12 \pm 0.67$ and $19.43 \pm 0.56 \mathrm{~g} / \mathrm{rat} /$ day for $\mathrm{D}_{0}, \mathrm{D}_{1}$ and $\mathrm{D}_{2}$, respectively at the completion of study. The Figure 1 illustrated maximum feed intake at initiation in $\mathrm{D}_{0}(16.78 \pm 0.62$ $\mathrm{g} / \mathrm{rat} /$ day $)$ followed by $\mathrm{D}_{1}(16.21 \pm 0.65 \mathrm{~g} / \mathrm{rat} /$ day $)$ and $\mathrm{D}_{2}(15.49 \pm 0.58 \mathrm{~g} / \mathrm{rat} / \mathrm{day})$ whereas similar trend was observed at the termination of study II i.e. $\mathrm{D}_{0}(24.59 \pm$ $0.47 \mathrm{~g} / \mathrm{rat} /$ day $)$ trailed by $\mathrm{D}_{1}(22.34 \pm 0.45 \mathrm{~g} / \mathrm{rat} /$ day $)$ and $\mathrm{D}_{2}(21.16 \pm 0.44 \mathrm{~g} / \mathrm{rat} / \mathrm{day})$. Means relating to drink intake revealed a gradual rise as a function of treatments and time. In this context, minimum intake was noticed in $\mathrm{D}_{0}$ followed by $\mathrm{D}_{1}$ and $\mathrm{D}_{2}$ i.e. $18.51 \pm$ $0.37 \& 23.37 \pm 0.64,18.69 \pm 0.32 \& 24.18 \pm 0.56$ and $18.74 \pm 0.41 \& 24.63 \pm 0.59 \mathrm{~mL} / \mathrm{rat} /$ day, respectively at $1^{\text {st }}$ and $8^{\text {th }}$ week of the study I. Conversely, in study II (hyperglycemic rats), $\mathrm{D}_{0}$ expounded the highest drink intake $22.49 \pm 1.03 \mathrm{~mL} / \mathrm{rat} /$ day followed by $\mathrm{D}_{1}$ $(22.37 \pm 0.95 \mathrm{~mL} / \mathrm{rat} /$ day $)$ and $\mathrm{D}_{2}(22.31 \pm 0.98 \mathrm{~mL} / \mathrm{g} /$ rat) at initiation of the trial. Whereas, increase in drink intake was recorded due to the effect of time as 31.62 $\pm 0.78,30.13 \pm 0.89$ and $29.20 \pm 0.83 \mathrm{~mL} / \mathrm{rat} /$ day in $\mathrm{D}_{0}, \mathrm{D}_{1}$ and $\mathrm{D}_{2}$, respectively at termination (Figure 2).

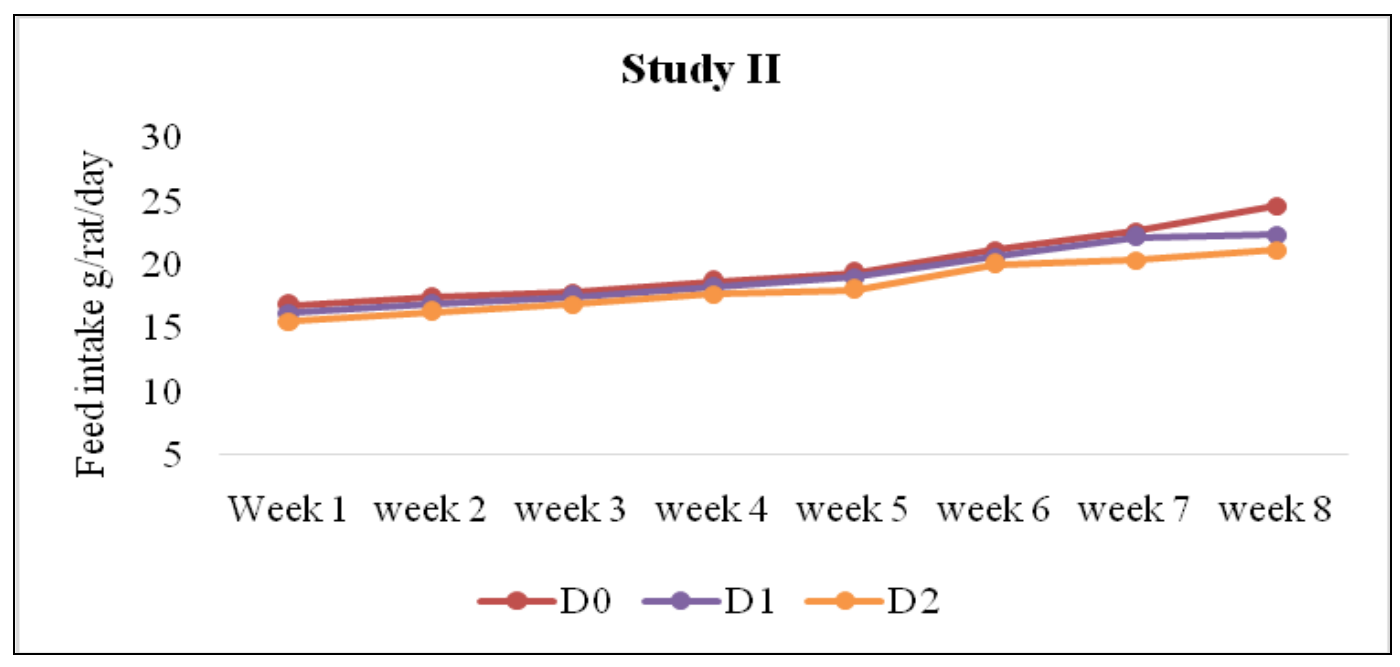

Fig. 1: Feed Intake in Study II (g/rat/day).

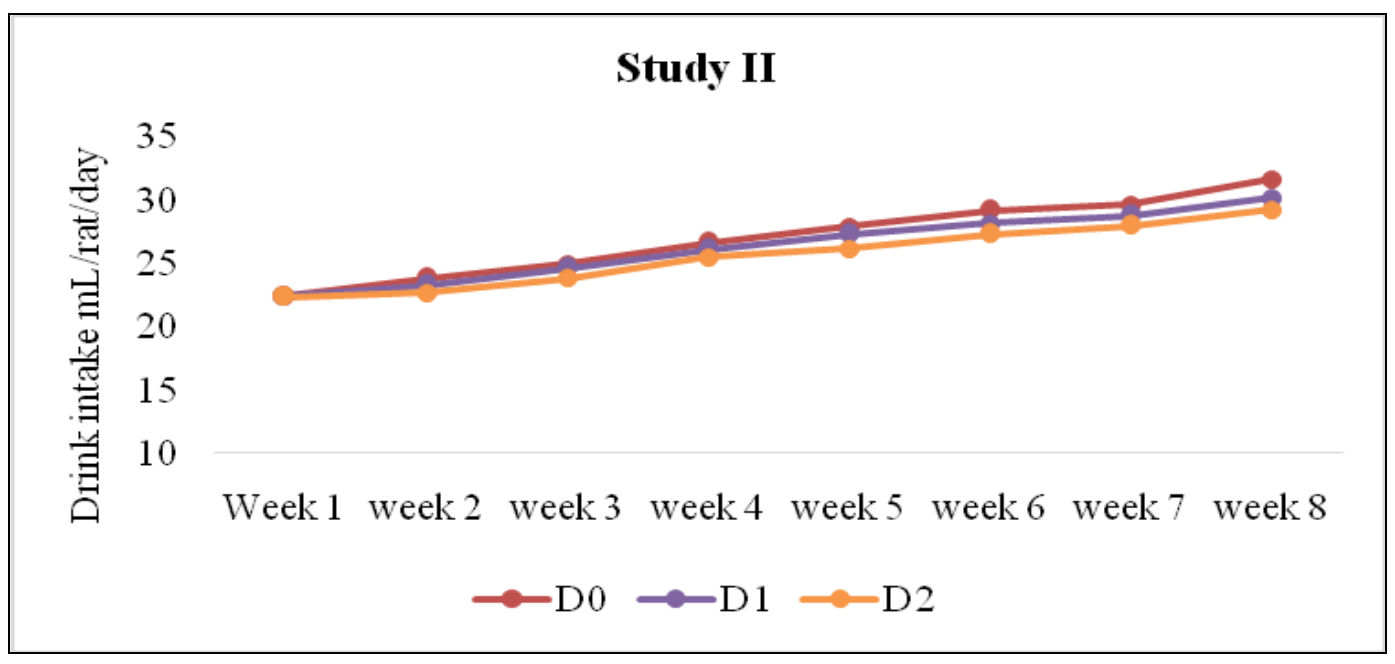

Fig. 2: Drink Intake in Study II ( $\mathrm{mL} / \mathrm{rat} /$ day). 


\section{Study II}

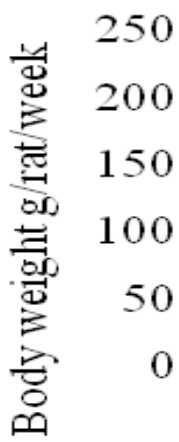

Week 1 week 2 week 3 week 4 week 5 week 6 week 7 week 8

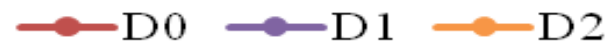

Fig. 3: Body Weight in Study II (g/rat/week).

Table 4: Effect of Diets on Glucose ( $\mathrm{mg} / \mathrm{dL}$ ) of Rats.

\begin{tabular}{|l||c||c||c||c||}
\hline \multirow{2}{*}{ Studies } & \multicolumn{3}{|c||}{ Treatments } & \multirow{2}{*}{ F value } \\
\cline { 2 - 5 } & $\mathbf{D}_{\mathbf{0}}$ & $\mathbf{D}_{\mathbf{1}}$ & $\mathbf{D}_{\mathbf{2}}$ & \\
\hline \hline Study I & $90.98 \pm 5.07$ & $89.14 \pm 4.72$ & $87.75 \pm 4.13$ & $1.16^{\mathrm{NS}}$ \\
\hline \hline Study II & $138.45 \pm 6.69 \mathrm{a}$ & $124.69 \pm 5.45 \mathrm{~b}$ & $122.32 \pm 5.18 \mathrm{~b}$ & $35.4^{* *}$ \\
\hline
\end{tabular}

$(p \leq 0.05)$

NS = Non-significant: ** = Highly significant; Study I:Normal rats, Study II: Hyperglycemic rats,

$\mathrm{D}_{0}$ : Control diet, $\mathrm{D}_{1}$ : Diet containing nutraceutical ${ }_{\mathrm{CSE}}, \mathrm{D}_{2}$ : Diet containing nutraceutical $\mathrm{SFE}_{\mathrm{SF}}$

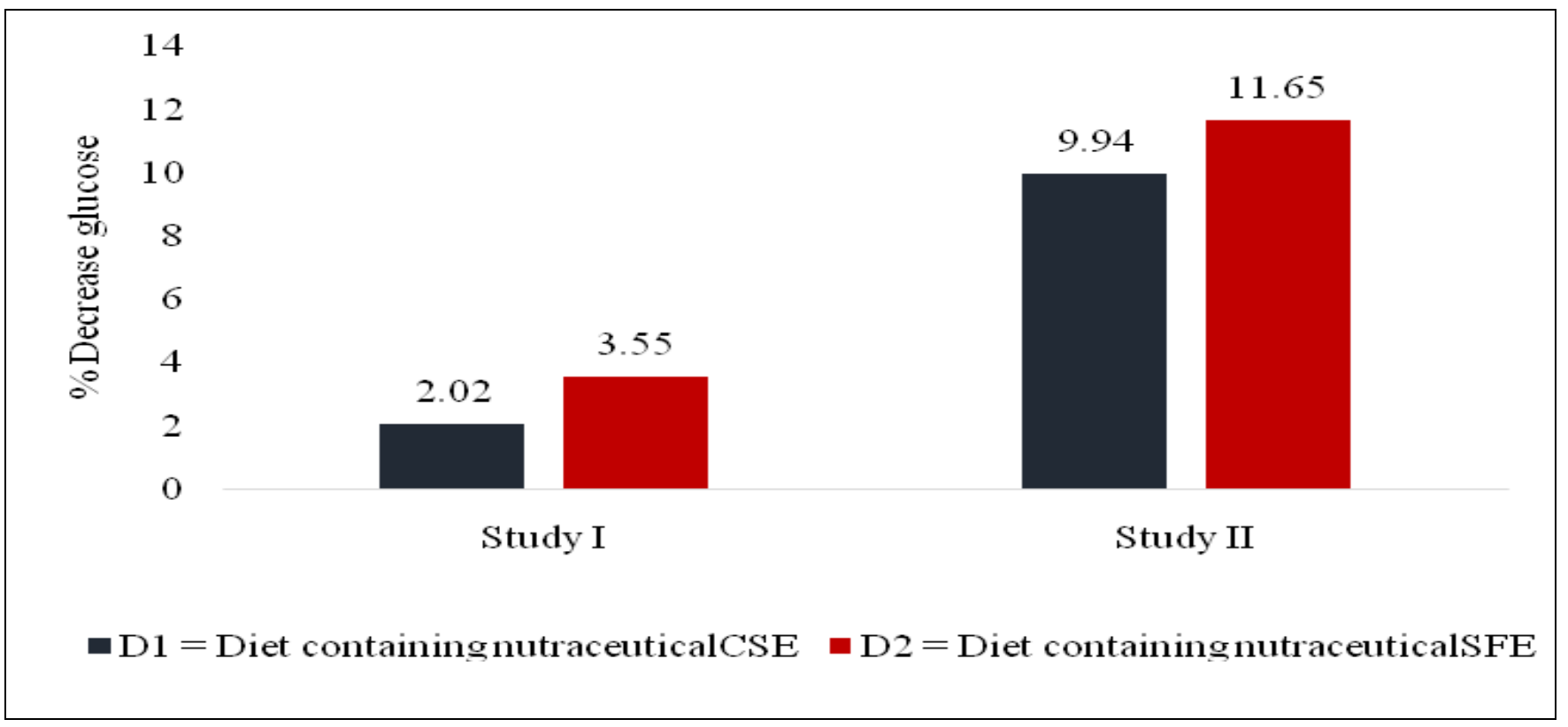

Fig. 4: Percent Decrease in Glucose as Compared to Control. 
Table 5: Effect of Diets on Insulin $(\mu U / m L)$ of Rats.

\begin{tabular}{|c|c|c|c|c|}
\hline \multirow{2}{*}{ Studies } & \multicolumn{3}{|c|}{ Treatments } & \multirow{2}{*}{ F value } \\
\hline & $\overline{D_{0}}$ & $\overline{D_{1}}$ & $\overline{D_{2}}$ & \\
\hline $\begin{array}{l}\text { Study I } \\
\end{array}$ & $7.84 \pm 0.51$ & $7.99 \pm 0.48$ & $8.03 \pm 0.60$ & $3.05^{\mathrm{NS}}$ \\
\hline Study II & $13.47 \pm 0.63 \mathrm{~b}$ & $\overline{c 14.41 \pm 0.65 \mathrm{a}}$ & $\overline{c 14.52 \pm 0.64 \mathrm{a}}$ & $11.6^{*}$ \\
\hline
\end{tabular}

$(p \leq 0.05)$

NS = Non-significant: * = Significant; Study I: Normal rats, Study II: Hyperglycemic rats,

$\mathrm{D}_{0}$ : Control diet, $\mathrm{D}_{1}$ : Diet containing nutraceutical ${ }_{\mathrm{CSE}}, \mathrm{D}_{2}$ : Diet containing nutraceutical $\mathrm{SFE}_{\mathrm{SF}}$

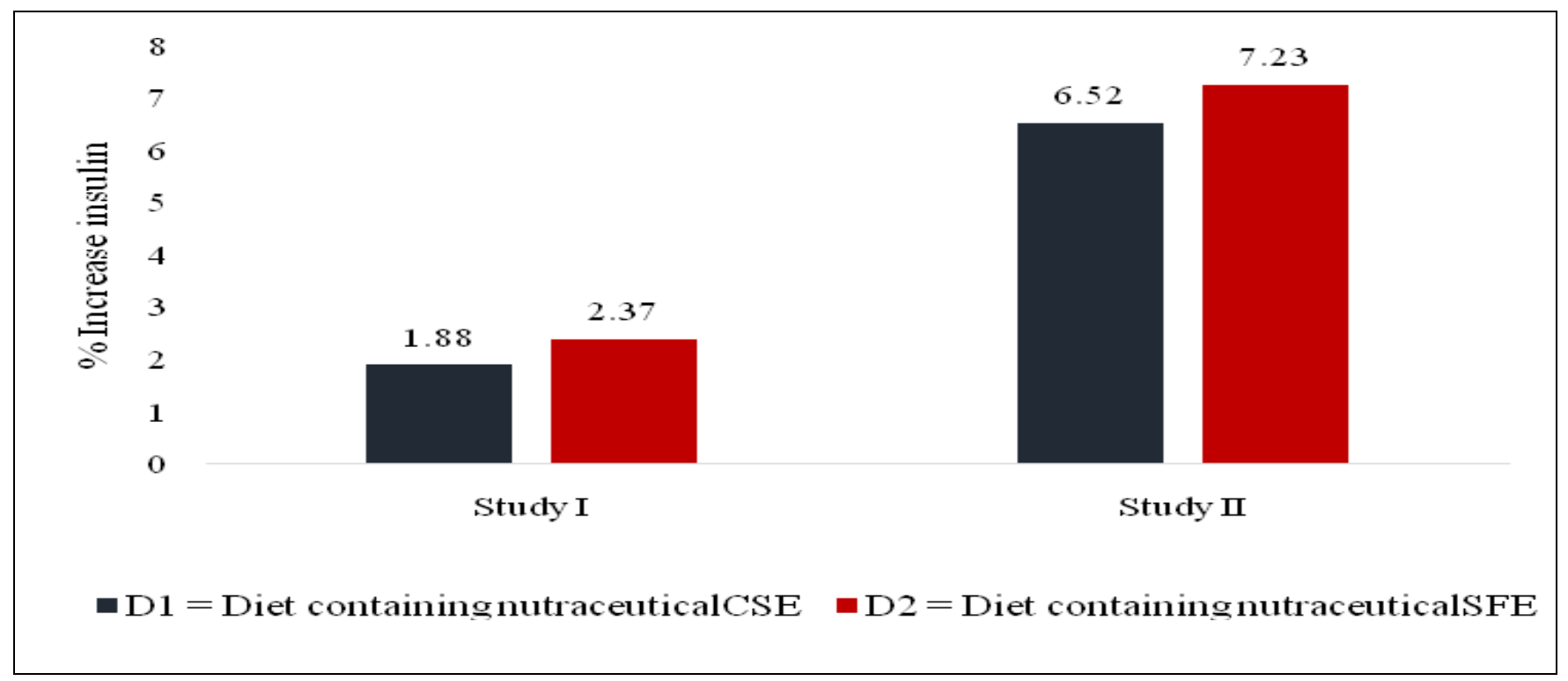

Fig. 5: Percent Increase in Insulin as Compared to Control.

The recorded body weights of groups $\mathrm{D}_{0}, \mathrm{D}_{1}$ and $\mathrm{D}_{2}$ (Study I; Normal rats) were $131 \pm 4.83,135 \pm 5.62$ and $137 \pm 5.14 \mathrm{~g} / \mathrm{rat}$, respectively that raised to 235.67 $\pm 4.19,244.81 \pm 3.73$ and $253 \pm 4.68 \mathrm{~g} /$ rat till the end of trial. The study II (Hyperglycemic rats) depicted initial body weight of $\mathrm{D}_{0}, \mathrm{D}_{1}$ and $\mathrm{D}_{2}$ groups as $145 \pm$ $5.76,142.15 \pm 5.08$ and $139 \pm 4.25 \mathrm{~g} /$ rat, correspondingly (Figure 3). However, at the end of trial resultant body weights were $207 \pm 6.63,225.89 \pm 7.14$ and $238.12 \pm 8.49 \mathrm{~g} / \mathrm{rat}$ for $\mathrm{D}_{0}, \mathrm{D}_{1}$ and $\mathrm{D}_{2}$, respectively.

Means for glucose in study I (normal rats) showed values $90.98 \pm 5.07,89.14 \pm 4.72$ and $87.75 \pm 4.13$ $\mathrm{mg} / \mathrm{dL}$ for $\mathrm{D}_{0}, \mathrm{D}_{1}$ and $\mathrm{D}_{2}$ groups, respectively. Mean glucose concentration for $\mathrm{D}_{0}$ group in study II was
$138.45 \pm 6.69 \mathrm{mg} / \mathrm{dL}$ that declined substantially to $124.69 \pm 5.45 \mathrm{mg} / \mathrm{dL}$ in $\mathrm{D}_{1}$. Whereas the lowest glucose level was noticed for $\mathrm{D}_{2}$ as $122.32 \pm 5.18 \mathrm{mg} / \mathrm{dL}$ in hyperglycemic rats (Table 4).It is obvious from results that diets containing nutraceutical ${ }_{\mathrm{SFE}}\left(\mathrm{D}_{2}\right)$ performed better against glucose related deformities than diets containing nuteraceutical ${ }_{\mathrm{CSE}}\left(\mathrm{D}_{1}\right)$ and control diet $\left(D_{0}\right)$. The Figure 4 depicted highest percent decline in glucose for study II i.e. 9.94 and $11.65 \%$ for $\mathrm{D}_{1}$ and $\mathrm{D}_{2}$, respectively. However, study I showed a non-significant decline in glucose level in groups; $\mathrm{D}_{1}(2.02 \%)$ and $\mathrm{D}_{2}(3.55 \%)$ as compared to control.

Means related to study I (Table 5) elucidated that minimum insulin level was $7.84 \pm 0.51 \mu \mathrm{U} / \mathrm{mL}\left(\mathrm{D}_{0}\right)$ that increased to $7.99 \pm 0.48 \mu \mathrm{U} / \mathrm{mL}\left(\mathrm{D}_{1}\right)$ and $8.03 \pm$ 
$0.60 \mu \mathrm{U} / \mathrm{mL}\left(\mathrm{D}_{2}\right)$. The study II indicated a momentous rise in insulin level; maximum level was recorded for $\mathrm{D}_{2}(14.52 \pm 0.64 \mu \mathrm{U} / \mathrm{mL})$ followed by $\mathrm{D}_{1}(14.41 \pm 0.65$ $\mu \mathrm{U} / \mathrm{mL})$ and $\mathrm{D}_{0}(13.47 \pm 0.63 \mu \mathrm{U} / \mathrm{mL})$. It is noticeable from the Figure 5 that $\mathrm{D}_{2}$ group showed maximum rise for insulin $(2.37 \%)$ trailed by $\mathrm{D}_{1}(1.88 \%)$ as compared to control $\left(\mathrm{D}_{0}\right)$ in study I. Accordingly, the study II presented a significant increase for insulin in the groups $\mathrm{D}_{1}$ and $\mathrm{D}_{2}$ as 6.52 and $7.23 \%$.

In current investigation, the effect of cinnamaldehyde was evaluated on lipoprotein diagnostic indicators as total cholesterol, LDL, HDL and triglycerides in normal and hyperglycemic rats. It is evident from the $\mathrm{F}$ value that treatments exhibited significant variations on cholesterol level of various rats groups in study II whereas non-significant differences were observed in study I.The means for normal rats (study I) presented diminishing trend for cholesterol in $\mathrm{D}_{0}(82.30 \pm 3.95$ $\mathrm{mg} / \mathrm{dL})$ trailed by $\mathrm{D}_{1}(79.84 \pm 4.23 \mathrm{mg} / \mathrm{dL})$ and $\mathrm{D}_{2}$ $(79.36 \pm 4.12 \mathrm{mg} / \mathrm{dL})$. The cholesterol level in study II (hyperglycemic rats) showed maximum decline in $\mathrm{D}_{2}$ $(91.90 \pm 4.64 \mathrm{mg} / \mathrm{dL})$, whilst $\mathrm{D}_{1}$ and $\mathrm{D}_{0}$ had values as $93.51 \pm 3.87$ and $99.77 \pm 4.26 \mathrm{mg} / \mathrm{dL}$, respectively. In study II, the hyperglycemic rats exhibited a decrease in cholesterol level from $7.89 \%\left(\mathrm{D}_{2}\right)$ to $6.27 \%\left(\mathrm{D}_{1}\right)$.

In present research project, $\mathrm{D}_{2}$ (diet containing nutraceutical $_{\mathrm{SFE}}$ ) caused maximum reduction in LDL follo-

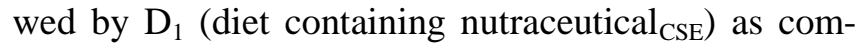
pared to $\mathrm{D}_{0}$ (control diet). In study I, maximum LDL level was observed in $\mathrm{D}_{0}(31.21 \pm 2.05 \mathrm{mg} / \mathrm{dL})$ followed by $\mathrm{D}_{1}(30.08 \pm 1.77 \mathrm{mg} / \mathrm{dL})$ group however, minimum level $(29.96 \pm 1.56 \mathrm{mg} / \mathrm{dL})$ for this trait was in $\mathrm{D}_{2}$. In study II higher reduction was exhibited by $\mathrm{D}_{2}$ $(11.37 \%)$ trailed by lower decrease in $\mathrm{D}_{1}(10.86 \%)$ with mean $\mathrm{LDL}$ values for $\mathrm{D}_{0}(45.57 \pm 2.14 \mathrm{mg} / \mathrm{dL})$ that momentously reduced to $40.62 \pm 1.92$ and $40.39 \pm$ $1.33 \mathrm{mg} / \mathrm{dL}$ in $\mathrm{D}_{1}$ and $\mathrm{D}_{2}$, respectively.

Statistical analysis (F value) indicated that treatments imparted significant differences on high density lipoprotein (HDL) in hyperglycemic rats (study II). However, study I (normal rats) evidenced non-momentous variations due to the effect of diets. Means for HDL values in study I were $33.46 \pm 1.93,34.15 \pm 2.08$ and $34.37 \pm 2.15 \mathrm{mg} / \mathrm{dL}$ in $\mathrm{D}_{0}, \mathrm{D}_{1}$ and $\mathrm{D}_{2}$ groups, respectively. Nonetheless in study II, lowest HDL level was recorded in $\mathrm{D}_{0}(42.68 \pm 1.51 \mathrm{mg} / \mathrm{dL})$ that significantly uplifted to $43.99 \pm 1.27$ and $44.20 \pm 1.69 \mathrm{mg} / \mathrm{dL}$ in $\mathrm{D}_{1}$ and $\mathrm{D}_{2}$ groups.

Cinnamaldehyde can reduce triglyceride level in hyperglycemic rats. Means for triglyceride in study I indicated non-momentous declining trend for $\mathrm{D}_{0}, \mathrm{D}_{1}$ and $\mathrm{D}_{2}$ as $68.32 \pm 4.21,66.63 \pm 4.05$ and $66.25 \pm 3.94$ $\mathrm{mg} / \mathrm{dL}$, respectively. Triglyceride level in study II revealed a diminishing tendency for all groups; maximum value in $\mathrm{D}_{0}(75.69 \pm 3.18 \mathrm{mg} / \mathrm{dL})$ followed by $\mathrm{D}_{1}$ $(71.04 \pm 2.66 \mathrm{mg} / \mathrm{dL})$ and $\mathrm{D}_{2}(70.50 \pm 2.97 \mathrm{mg} / \mathrm{dL})$.

\section{Discussion}

In a study, Shatwan et al. ${ }^{20}$ assessed the effect of cinnamon extract on feed intake of male Wistar rats. They were of the view that feed intake was significantly higher $(35.99 \pm 3.17$ and $30.23 \pm 3.58 \mathrm{~g})$ in diabetic and cinnamon treated rats as compared to control $(25.93 \pm 1.33 \mathrm{~g})$ group. This increment in feed intake was due to the increase of neuropeptides YmRNA and reduced leptin receptors activity with inadequate insulin supply ultimately reducing the weight gain in diabetic rats. The previous findings of Anand et al. ${ }^{21}$ further strengthened the present results. They deduced the significant increase of about 4.37 times $(175 \pm 16$ $\mathrm{mL} /$ day) in fluid intake of untreated diabetic rats when compared with control $(40 \pm 3.2 \mathrm{~mL} /$ day $)$. They also illuminated the inverse relation between the oral administration of cinnamon@ $\mathbf{2 0} \mathrm{mg} / \mathrm{kg}$ body weight and fluid intake, which resulted in decreased $(74 \pm 8 \mathrm{~mL} /$ day) fluid intake in diabetic rats. The results of present research regarding body weight in cinnamaldehyde (CND) administered male wistar rats are in agreement with the findings of Anand et al. ${ }^{22}$ They reported significant decrease $37.9 \%$ in body weight of STZ induced diabetic rats after 60 days induction. They also noticed the restoration in body weight $209 \pm 10 \mathrm{~g}$ after oral intake of cinnamaldehyde $(20 \mathrm{mg} / \mathrm{kg})$ to diabetic rats near to control $224 \pm 16 \mathrm{~g}$.

The results relating to glucose reduction with cinnamon polyphenols are in harmony with the earlier work of Cheng et al. ${ }^{23}$ In a 12 weeks trial, they obse- 
rved significant reduction in fasting blood glucose (FBG) level as $0.3,14.6$ and $18.9 \%$, respectively in a dose dependent manner.In hyperglycemic condition, insulin resistance causes dysregulation of gluconeogenesis in hepatic tissues which results in elevated glucose level. Cinnamaldehyde helps to reduce blood glucose level by increasing insulin release and inhibiting the gene expression of phosphoenolpyruvatecarboxykinase \& glucose-6-phosphatase. Later, Sailesh and Padmanabha, ${ }^{24}$ examined the hypoglycemic effects of cinnamon bark extract in alloxan induced diabetic rats and inferred that cinnamon polyphenols reduced blood glucose level in a 21 days trial. The role of superoxide dismutase (SOD) and glutathione peroxidase (GSH-Px) to scavenge oxygen free radicals and pancreatic tissue protection form oxidative damage is well known. In diabetic mice, cinnamon polyphenols enhances SOD and GSH-Px activities and decreases malondialdehyde (MDA) contents in pancreatic tissue thus provide beneficial effects against hyperglycemia. ${ }^{25}$

In a research study, Ismail ${ }^{26}$ evaluated the variations in insulin hormone level with provision of different levels i.e. 100 and $200 \mathrm{mg} / \mathrm{kg}$ body weight of cinnamon extracts. He expounded progressive increase in the serum insulin level in a dose dependent manner with minimum insulin level $0.89 \pm 0.13 \mathrm{ng} / \mathrm{mL}$ in untreated diabetic rats which substantially increased to $2.43 \pm 0.12 \mathrm{ng} / \mathrm{mL}$ in rats treated with cinnamon extract @ $200 \mathrm{mg} / \mathrm{kg}$ which further confirmed our results.

The present trend for serum cholesterol reduct-ion is strengthened by the efficacy study of IM et al. $^{27}$ Ethanolic extract of cinnamon polyphenols elucidated a marked reduction in hypertriglyceridemia and hypercholesterolemia with $42.79 \%$ dec-rease in total cholesterol level in group treated with $70 \%$ polyphenol contents as compared to diabetic control. According to another study, cinnamon pro-vides protection against hypercholesterolemia by reducing the serum cholesterol level from $91.50 \pm 9.26$ to 76.75 $\pm 5.46 \mathrm{mg} / \mathrm{dL}$ in high cholesterol fed and cinnamontreated white male albino rats. ${ }^{28}$

Cinnamon ability to reduce serum LDL cholesterol level is supported by the work of Askari et al. ${ }^{29}$ They concluded that cinnamon intervention results in substantial diminution $55.8 \pm 40.8 \mathrm{mg} / \mathrm{dL}$ in LDL cholesterol as compared to placebo control $90.3 \pm 17.7$ $\mathrm{mg} / \mathrm{dL}$ in patients suffering from non-alcoholic fatty liver disease. The outcomes of Hasanein et al. ${ }^{30}$ strengthened the results of recent study as they observed an elevated level of HDL as $34.06 \pm 1.08 \mathrm{mg} / \mathrm{dL}$ in rats fed with high fat diet treated with aqueous cinnamon extracts.In a study researchers explicated the boosting effect of cinnamon polyphenols on antioxidant ability of diabetic mice against hyperlipidemia. They also recorded substantial reduction in serum triglyceride level of CPS (cinnamon polyphenols) treated mice at the end of study. ${ }^{31}$

\section{Conclusion}

Prevention of various metabolic syndromes by using different dietary patterns has become a major health concern worldwide especially in developing countries like Pakistan. In this milieu, cinnamon (Cinnamomumzeylanicum) provides a wide range of nutraceuticals especially cinnamaldehyde. The current study was an effort to assess the therapeutic worth of cinnamaldehyde to cope with hyperglycemia. In present study,reduction in glucose level was more in rats fed with nutraceutical ${ }_{S F E}$ diet $\left(D_{2}\right)$ as compared to nutraceutical ${ }_{C S E}$ diet $\left(D_{1}\right)$ followed by control diet $\left(D_{0}\right)$. In the nutshell, cinnamaldehyde enrichment/ supplementation should be encouraged at mass level and consumer awareness regarding diet based therapies should be promoted.

\section{Acknowledgements}

We are highly grateful to Higher Education Commission (HEC), Government of Pakistan for providing financial support to carry out this research.

\section{References}

1. Butt MS, Sultan MT. Ginger and its health claims: molecular aspects. Critical Reviews in Food Science and Nutrition. 2011;51(5):383-393.

2. Rio DD, Rodriguez-Mateos A, Spencer JP, Tognolini M, Borges G, Crozier A. Dietary (poly) phenolics in human health: Structures, bioavailability and evidence of protective effects against chronic diseases. Antioxidants and Redox Signaling. 2013;18(14):1818-1892.

3. Rubio L, Motilva M, Romero M. Recent advances in biologically active compounds in herbs and spices: a review of the most effective antioxidant and anti-inflammatory active principles. Critical Reviews in Food Science and Nutrition. 2013;53(9):943-953.

4. Sangal A. Role of cinnamon as beneficial antidiabetic food adjunct: a review. Advances in Applied Science Research. 2011;2(4):440-450. 
5. Jayaprakasha GK, Rao LJM. Chemistry, biogenesis, and biological activities of Cinnamomumzeylanicum. Critical Reviews in Food Science and Nutrition. 2011; 51(6):547-562.

6. Kim SH, Hyun SH, Choung SY. Antioxidative effects of Cinnamomi cassia and Rhodiolarosea extracts in liver of diabetic mice. Biofactor. 2006;26(3):209-219.

7. Crawford P, Thai C, Obholz J, Schievenin J, True M, Shah SA, et al. Assessment of the effect of lifestyle intervention plus water-soluble cinnamon extract on lowering blood glucose inpre-diabetics, a randomized, double-blind, multicenter, placebo controlled trial: study protocol for a randomized controlled trial. Trial. 2016;5(9):17-19.

8. Wild S, Roglic G, GreenA, Sicree R, King H. Global prevalence of diabetes: Estimates for the year 2000 and projections for 2030. Diabetes Care. 2004;27(10): 1047-1053.

9. Busija DW, Miller AW, Katakam P, Erdos B. Adverse effects of reactive oxygen species on vascular reactivity in insulin resistance. Antioxidants and Redox Signaling. 2006;8(7):1131-1140.

10. El-Baroty GS, El-Baky HHA, Farag RS, Saleh MA. Characterization of antioxidant and antimicrobial compounds of cinnamon and ginger essential oils. African Journal of Biochemistry Research. 2010;4 (6):167 174.

11. Mahfouz MH, Ghanem MH, Mohamed MA. Modulation of insulin receptor substrate-1 and some inflammatory variables in hyperinsulinemic rats treated with cinnamon extract.American Journal of Biochemistry and Biotechnology. 2010;6 (1):11-18.

12. Mariod AA, AL-Naqeb G, Ismail M. Monechmaciliatummethanolic extract regulates low density lipoprotein receptor and 3-hydroxy-3-methylglutaryl coenzyme A reductase genes expression in HepG2 cells. African Journal of Biotechnology, 2010; 9 (36): 5813-5819.

13. Marongiu B, Piras A, Porcedda S, Tveri E, Sanjust E, Meli M, et al.Supercritical $\mathrm{CO}_{2}$ Extract of Cinnamomumzeylanicum: Chemical characterization and Antityrosinase activity. Journal of Agricultural and Food Chemistry, 2007; 55 (24): 10022-10027.

14. Wolf BW, Weisbrode SE. Safety evaluation of an extract from Salaciaoblonga. Food and Chemical Toxicology, 2003; 41(6):867-874.

15. Sailesh KS, Padmanabha A. A comparative study of the anti-diabetic effect of oral administration of cinnamon, Nutmeg and peppermint in wistar albino rats. International Journal of Health Science Research. 2014;4 (2):61-67.

16. Ahn J, Choi W, Kim S, Ha T. Anti-diabetic effect of watermelon (Citrullus vulgaris Schrad) on streptozotocin-induced diabetic mice. Food Science and Biotechnology. 2011;20(1):251-254.

17. Vafa M, Mohammadi F, Shidfar F, Sormaghi MHS, Heidari I, Golestan B, et al. Effects of cinnamon con- sumption on glycemic status, lipid profile and body composition in type 2 diabetic patients. International Journal of Preventive Medicine. 2012;3(1):531-536.

18. Alshatwi AA, Al-Obaaid MA, Al-Sedairy SA, Al-Assaf $\mathrm{AH}$, Zhang JJ, Lei KY. Tomato powder is more protective than lycopene supplement against lipid peroxidation in rats. Nutrition Research. 2010;30(1):66-73.

19. Steel RGD, Torrie JH, Dickey D. Principles and Procedures of Statistics: A Biometrical Approach. 3rd Ed. McGraw Hill Book Co Inc, NY, USA. 1997.

20. Shatwan IA, Ahmed LA, Badkook MM. Effect of barley flour, crude cinnamon, and their combination on glycemia, dyslipidemia, and adipose tissue hormones in Type 2 diabetic rats. Journal of Medicinal Food. 2013; 16(7):656-662.

21. Anand P, Murali KY, Tandon V, Murthy PS, Chandra R. Insulinotropic effect of cinnamaldehyde on transcriptional regulation of pyruvate kinase, phosphoenol pyruvate carboxykinase and GLUT4 translocation in experimental diabetic rats. Chemico-Biological Interaction. 2010;186(1):72-81.

22. Anand P, Murali KY, Tandon V, Murthy PS, Chandra R. Insulinotropic effect of cinnamaldehyde on transcriptional regulation of pyruvate kinase, phosphoenol pyruvate carboxykinase and GLUT4 translocation in experimental diabetic rats. Chemico-Biological Interaction. 2010;186(1):72-81.

23. Cheng DM, Kuhn P, Pouley A, Rojo LE, Lila MA, Raskin I. In vivo and in vitro antidiabetic effects of aqueous cinnamon extract and cinnamon polyphenolenhanced food matrix. Food Chemistry. 2012;135(4): 2994-3002.

24. Sailesh KS, Padmanabha A. A comparative study of the anti-diabetic effect of oral administration of cinnamon, Nutmeg and peppermint in wistar albino rats. International Journal of Health Science Research. 2014;4 (2):61-67.

25. Kim JO, KimKS, Lee GD, Kwon JH. Antihyperglycemic and antioxidative Effects of new herbal formula in streptozotocin-induced diabetic rats. Journal of Medicinal Food. 2009;12(4):728-735.

26. Ismail NS. Protective effects of aqueous extracts of cinnamon and ginger herbs against obesity and diabetes in obese diabetic rat. World Journal of Dairy and Food Science. 2014;9(2):145-153.

27. IM KK, Issac A, Ninan E, Kuttan R, Maliakel B. Enhanced anti-diabetic activity of polyphenol rich de-coumarinated extracts of Cinnamomum cassia. Journal of functional Foods. 2014;10(1):54-64.

28. Amin KA, El-Twab TMA. Oxidative markers, nitric oxide and homocysteine alteration in hypercholesterolemic rats: role of atorvastatin and cinnamon. International Journal of Clinical and Experimental Medicine. 2009;2(3):254-265.

29. Askari F, Rashidkhani B, Hekmatdoost A. Cinnamon may have therapeutic benefits on lipid profile, liver 
enzymes, insulin resistance, and high-sensitivity C-reactive protein in nonalcoholic fatty liver disease patients. Nutrition Research. 2014;34 (2): 143-148.

30. Hasanein MA, Gawad SHA, El-Megeid AAA. Effect of water extract prepared from green tea, black tea and cinnamon on obese rats suffering from diabetes. World Applied Science Journal. 2012;20(7):976-987.
31. Li R, Liang T, Xu L, Li Y, Zhang S, Duan X. Protective effect of cinnamon polyphenols against STZ-diabetic mice fed high-sugar, high-fat diet and its underlying mechanism. Food and Chemical Toxicology. 2013;51 (1):419-425. 